\title{
Effectiveness of highly active antiretroviral therapy using non-brand name drugs in Brazil
}

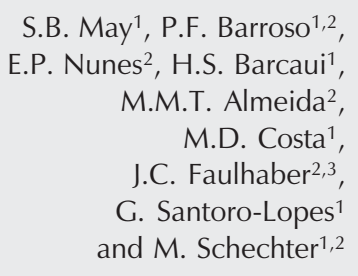

S.B. May ${ }^{1}$, P.F. Barroso ${ }^{1,2}$, E.P. Nunes ${ }^{2}$, H.S. Barcaui ${ }^{1}$, M.M.T. Almeida², M.D. Costa ${ }^{1}$, J.C. Faulhaber ${ }^{2,3}$, G. Santoro-Lopes ${ }^{1}$ and M. Schechter ${ }^{1,2}$

\author{
${ }^{1}$ Serviço de Doenças Infecciosas e Parasitárias, Departamento de Medicina Preventiva, \\ Hospital Universitário Clementino Fraga Filho, Faculdade de Medicina, \\ Universidade Federal do Rio de Janeiro, Rio de Janeiro, RJ, Brasil \\ ${ }^{2}$ Projeto Praça Onze, Hospital Escola São Francisco de Assis, \\ Universidade Federal do Rio de Janeiro, Rio de Janeiro, RJ, Brasil \\ ${ }^{3}$ Instituto de Matemática, Universidade do Estado do Rio de Janeiro, \\ Rio de Janeiro, RJ, Brasil
}

\section{Correspondence}

P.F. Barroso

Serviço de DIP

Hospital Universitário

Clementino Fraga Filho, UFRJ

Av. Brigadeiro Trompowski, $s / \mathrm{n}$

21941-950 Rio de Janeiro, RJ

Brasil

E-mail: paulofbarr@hucff.ufrj.br

Presented in part at the $3 \mathrm{rd}$ International Aids Society Conference on HIV Pathogenesis and Treatment, Rio de Janeiro, July 24-27, 2005.

Research supported in part by a CNPq grant to M. Schechter, and a FAPERJ grant to P.F. Barroso.

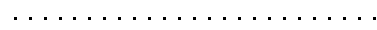

Received May 12, 2006 Accepted February 2, 2007

\begin{abstract}
In Brazil, HIV-infected individuals receive drugs (including nonbrand name drugs which comprise locally produced generics and drugs that have not been tested in bioequivalence trials) free of charge from the government. The objective of the present study was to evaluate the effectiveness of highly active antiretroviral therapy (HAART) in Rio de Janeiro, Brazil, where non-brand drugs are widely used. For this purpose, we estimated the proportion of subjects with virologic failure (plasma HIV viral load greater than 400 copies $/ \mathrm{mL}$ at 6 months after initiation of treatment). This was a retrospective cohort study of drug-naive HIV-infected subjects who initiated HAART. Subjects were included in the analysis if they were 18 years of age or older, were treatment naive, started HAART with a minimum of 3 drugs, and had available information on blood plasma HIV-1 viral load after 6 months on therapy. All subjects used antiretrovirals in dosing regimens recommended by the Brazilian National Advisory Committee for Antiretroviral Therapy. Chart reviews were conducted in three settings: at two public health outpatient units, at one clinical trial unit and at one private office. No comparisons of the effectiveness of non-brand name with the effectiveness of brand name drugs were made. We present results for 485 patients; of these, 354 (73\%), 55 $(11 \%)$, and $76(16 \%)$ were seen at the public health outpatient units, private office, and clinical trial unit, respectively. Virologic failure was observed in $119(25 \%)$ of the subjects. This study demonstrates the effectiveness of HAART in a setting where non-brand name drugs are widely used.
\end{abstract}

\section{Introduction}

Studies conducted in developed countries using brand name drugs have demonstrated that early virologic response after
Key words - HIV/AIDS

- Antiretroviral

- Non-brand name drugs

- Brazil

- Virologic failure 
the availability of non-brand name drugs, drastic price reductions of some brand name drugs, and some new initiatives of international agencies. In June 2005, the World Health Organization estimated that approximately one million individuals in developing countries were receiving HAART. This represents $15 \%$ of the estimated 6.5 million people in need of HAART in low- and middle-income countries (2-4). In Brazil, since 1996 virtually all HIV-infected individuals that are on treatment, including patients treated in private practice, receive their drugs free at public dispensaries. Drugs that are protected by patents are purchased exclusively from the patent holders. In addition, non-brand name drugs are also used. Non-brand name drugs include locally produced generic drugs (drugs that are bioequivalent to a brand name drug with respect to pharmacokinetic and pharmacodynamics properties as defined by Brazilian regulations) and locally produced drugs that have not been tested in bioequivalence trials. At present, the following antiretrovirals are bought exclusively from their patent holders: tenofovir, enteric-coated didanosine, efavirenz, nelfinavir, amprenavir, lopinavir/ritonavir, atazanavir, and enfurvitide. Abacavir has been licensed to a Brazilian manufacturer. Drugs that are not protected by applicable patent laws are purchased through public tenders. Thus, brand name and non-brand name zidovudine, lamivudine, didanosine, stavudine, nevirapine, saquinavir, indinavir, and ritonavir might be dispensed to patients, depending on the results of public bids by the suppliers.

Results of recent studies have suggested that virologic and immunological responses to HAART in developing countries are similar to those observed in high-income settings $(5-11)$. Nonetheless, there is relatively little information on the effectiveness of antiretroviral therapy including non-brand name drugs (12). We designed the present study to investigate virologic response 6 months after the initiation of HAART in drug-naive subjects treated in three different settings in Rio de Janeiro, Brazil: in two public health outpatient units (PHU) and in one private office (PO), where patients use a mixture of non-brand name and brand name drugs (see above), and in a clinical trial unit (CTU), where only brand name drugs are used.

The objective of the present study was to evaluate the effectiveness of HAART in Rio de Janeiro, Brazil, where non-brand drugs are widely used. For this purpose we estimated the proportion of subjects with virologic failure (VF). In addition, we evaluated predictors of VF.

\section{Patients and Methods}

This was a retrospective cohort study of drug-naive HIV-infected subjects who started HAART between 1996 and 2004 in Rio de Janeiro, Brazil. The institutional review board of the Hospital Universitário Clementino Fraga Filho (HUCFF)/School of Medicine of the Universidade Federal do Rio de Janeiro approved the study.

\section{Patients}

Study subjects came from 3 different settings: 2 PHU (HUCFF, a large teaching hospital of the Universidade Federal do Rio de Janeiro, and Centro Municipal de Saúde João Barros Barreto, a primary care facility run by the City of Rio de Janeiro Health Department), one CTU (Projeto Praça Onze, Universidade Federal do Rio de Janeiro), and the PO of one of the authors (MS). Subjects were included in the analysis if they were 18 years of age or older, were treatment naive and started HAART with a minimum of 3 drugs, and had available information on blood plasma HIV-1 viral load after 6 months on therapy. All subjects used antiretrovirals in dosing regimens recommended by the Brazilian National Advisory Committee for Antiretroviral thera- 
py of the Ministry of Health, Brazil.

\section{Study endpoint and exposure variables}

The primary endpoint of this study was VF at 6 months on HAART, which was defined as a plasma HIV load greater than 400 copies/mL 6 months (range: 3 to 9 months) after initiation of treatment. When more than one measurement was available, the one closest in time to 6 months on therapy was utilized. Exposure variables were age, gender, year of HAART introduction, type of combination regimen prescribed, setting where care was provided, and baseline CD4 cell count, CD4 percentage and HIV-1 viral load. No comparisons of the effectiveness of non-brand name with the effectiveness of brand name drugs were made. An intent-to-continue-treatment approach, which ignored subsequent therapy changes or interruptions, was used. Data were abstracted from charts by trained research assistants and entered in the database using the Teleform $6.1^{\circledR}$ software.

\section{Statistical analysis}

The main analysis was an evaluation of the determinants of $\mathrm{VF}$ at 6 months on HAART. Univariate analyses identified variables associated with VF. Categorical data were analyzed using the chi-square test or Fischer's exact test when appropriate. Continuous variables were analyzed using $t$-tests, when appropriate. HIV load in blood plasma was not normally distributed and therefore the data were log-transformed (base 10). Odds ratios (OR) and 95\% confidence intervals $(95 \% \mathrm{CI})$ were calculated. Univariate analysis identified variables to be included in the logistic multivariate analysis. Two indicator (dummy) variables were created to accommodate the 3 modes of health delivery. All reported $\mathrm{P}$ values are two-sided. SPSS $^{\circledR}$ for Windows 9.0 was used for data analysis.

\section{Results}

A total of 485 subjects were included in the analysis. The mean age at HAART initiation was 38 years and $308(64 \%)$ were males. Three hundred and fifty-four subjects (73\%) came from the PHU, 55 (11\%) from the PO and $76(16 \%)$ from the CTU. The median year of HAART introduction was 2001. Two hundred and eleven subjects (44\%) initiated a protease inhibitor (PI) containing regimen and $258(53 \%)$ initiated a non-nucleoside (NN) reverse transcriptase inhibitor-containing regimen (NNRTI), while 10 (2\%) were prescribed a three-nucleoside regimen and 6 (1\%) initiated a regimen containing both a PI and an NN. Median CD4 cell count and percentage at baseline were 174 cells $/ \mu \mathrm{L}$ and $12 \%$, respectively. Median baseline HIV-1 load was 82,550 copies/mL for the 260 subjects who had that measurement available. Table 1 shows the distribution of the selected variables by type of health delivery mode.

Mean baseline HIV-1 load was $4.19 \log _{10}$ for subjects prescribed a PI-containing HAART and $4.32 \log _{10}$ for those prescribed an NNRTI-containing HAART ( $\mathrm{P}=0.71, t$ test). Subjects prescribed a PI-containing regimen had a slightly lower CD4 count at baseline (mean 201 cells/ $\mu \mathrm{L}$ for the NNRTI group and 160 cells $/ \mu \mathrm{L}$ for the PI group, $\mathrm{P}=$ $0.02, t$-test).

Table 1. Distribution of selected variables among subjects seen in three health delivery settings.

\begin{tabular}{lccc}
\hline & PHU & PO & CTU \\
& $(\mathrm{N}=354)$ & $(\mathrm{N}=55)$ & $(\mathrm{N}=76)$ \\
\hline Age in years (mean $\pm \mathrm{SD})$ & $41 \pm 11$ & $46 \pm 12$ & $37 \pm 10$ \\
Male $(\%)$ & 59 & 80 & 72 \\
Median year of HAART introduction & 2000 & 2000 & 2001 \\
Pl containing HAART $(\%)$ & 53 & 37 & 11 \\
Median baseline HIV-1 load & 71,000 & 128,709 & 75,466 \\
Median baseline CD4 count (cells $/ \mu \mathrm{L})$ & 179 & 206 & 199 \\
\hline
\end{tabular}

HAART = highly active antiretroviral therapy; $\mathrm{PI}=$ protease inhibitor; $\mathrm{PHU}=$ public health unit; $\mathrm{PO}=$ private office; $\mathrm{CTU}=$ clinical trial unit. 


\section{Virologic failure at 6 months}

VF was observed in $119(25 \%)$ of the subjects. VF occurred in 104 (29\%), 3 (6\%) and $12(15 \%)$ of the subjects treated at PHU, PO and CTU, respectively. In univariate analysis, VF was associated with a lower baseline CD4 count (mean: 138 cells/ $\mu \mathrm{L} v s$ 201 cells $\left./ \mathrm{mm}^{3}, \mathrm{P}<0.01\right)$, higher baseline viral load (mean $4.12 \log _{10}$ vs $4.93 \log _{10}, \mathrm{P}=$ $0.003)$, therapy started before $2000(\mathrm{OR}=$ $2.71 ; 95 \% \mathrm{CI}=1.75-4.2)$, and use of PI $v s$ NNRTI (OR $=2.19 ; 95 \% \mathrm{CI}=1.43-3.37)$.

In the multivariate analysis, receiving care at the PO was associated with a significantly lower risk of $\mathrm{VF}(\mathrm{OR}=0.10 ; 95 \% \mathrm{CI}$ $=0.02-0.45$ for being treated at the PO) compared with treatment at PHU. The risk of VF was not significantly different between patients treated at the CTU and patients treated at the PHU $(\mathrm{OR}=0.82 ; 95 \% \mathrm{CI}$ $=0.39-1.70$ ). VF was independently associated with a lower baseline CD4 cell count/ $\mathrm{mm}^{3}$ and with initiation of HAART before 2000. Table 2 shows the final multivariate logistic model. Baseline HIV-1 load was not included in the model because a significant proportion of subjects did not have this measurement available. Nevertheless, in a model that included baseline HIV-1 load, the re-

Table 2. Multiple logistic regression analysis of determinants of virologic failure after 6 months on therapy.

\begin{tabular}{|c|c|c|}
\hline Characteristic & OR $(95 \% \mathrm{Cl})$ & $P$ value \\
\hline \multicolumn{3}{|l|}{ Antiretroviral regimen } \\
\hline NNRTI containing HAART & 1 & Reference \\
\hline PI containing HAART & $1.31(0.73-2.37)$ & 0.38 \\
\hline \multicolumn{3}{|l|}{ Year of HAART introduction } \\
\hline$\geq 2000$ & 1 & Reference \\
\hline$<2000$ & $2.37(1.28-4.41)$ & 0.006 \\
\hline Baseline CD4 count (cells/ $\mu \mathrm{L}$ ) & $0.996(0.993-0.997)$ & 0.016 \\
\hline \multicolumn{3}{|l|}{ Health delivery setting } \\
\hline Public health units & 1 & Reference \\
\hline Private clinic & $0.10(0.02-0.45)$ & 0.03 \\
\hline Clinical trial unit & $0.82(0.39-1.70)$ & 0.59 \\
\hline
\end{tabular}

OR $=$ odds ratio $95 \% \mathrm{Cl}=$ confidence interval at $95 \%$; NNRTI = non-nucleoside reverse transcriptase inhibitor; HAART $=$ highly active antiretroviral therapy; $\mathrm{PI}=$ protease inhibitor. sults obtained were similar to those presented here (data not shown).

\section{Discussion}

The main finding of the present study is that the virologic effectiveness of HAART in a developing country where non-brand name drugs are widely used is comparable to that reported in developed countries using brand name drugs $(13,14)$. Study participants started HAART with fairly low-baseline CD4 levels, a predictor of VF $(1,14)$. Nonetheless, VF at 6 months on therapy was observed in $25 \%$ of the subjects, a result that compares favorably to what has been reported in developed countries $(1,13)$. The main predictors of VF in our study were lower baseline CD4 counts, introduction of HAART before 2000 , and treatment not provided in a private office. The finding that lower baseline CD4 was an independent predictor of failure is consistent with reports from other settings $(1,14,15)$. Individuals who started HAART before 2000 had more than twice the chance of failing treatment than those who started treatment in more recent years, probably reflecting the introduction of efavirenz and the use of ritonavirboosted regimens becoming much more common over time (7).

Being treated at a private office was associated with a lower risk of virologic failure. In Brazil, patients treated at private offices also receive their drugs free at public dispensaries. Thus, they receive the same mixture of non-brand name and brand name drugs as patients treated in PHU. The reasons that may explain the lower failure rate at the $\mathrm{PO}$ were not investigated in the present study. Data on co-morbidities prior to initiation of treatment were not available for all patients. Nonetheless, given their higher socio-economic status, the lower VF rate observed at the $\mathrm{PO}$ may reflect a lower prevalence of co-morbidities associated with poverty, particularly tuberculosis. Additionally, 
patients at the PO are likely to have a higher educational level, more access to information and a closer doctor-patient relationship, factors that positively influence compliance with therapy (8). Further studies are necessary to confirm and investigate the reasons for the difference in effectiveness of HAART between patients treated at private offices and public clinics. These, in turn, may assist with the development of strategies to improve the effectiveness of HAART among lower income patients.

There are other limitations to the present study, including its retrospective design. A substantial proportion of patients from the PHU had to be excluded because of lack of viral load measurements. Finally, although it is highly likely that the vast majority of patients treated at the PHU and the PO received non-brand name drugs, we cannot be sure about this, since brand name and nonbrand name drugs might be dispensed, depending on the results of public bids.

\section{Acknowledgments}

The authors wish to thank all the patients who participated in this study and the Praça Onze Study Team. We also thank Dr. Marisa Tavares and Ms. Maria Fátima de Melo for performing the laboratory assays, and Andrea Christ, Fabio Leira, and Livio Souza for assistance with data collection.

\section{References}

1. Chene G, Sterne JA, May M, Costagliola D, Ledergerber B, Phillips AN, et al. Prognostic importance of initial response in HIV-1 infected patients starting potent antiretroviral therapy: analysis of prospective studies. Lancet 2003; 362: 679-686.

2. World Health Organization. Scaling up antiretroviral therapy in resource-limited settings: treatment guidelines for a public health approach - 2003 revision. http://www.who.int/hiv/pub/prev_care/en/ arvrevision2003en.pdf.

3. Desvarieux M, Landman R, Liautaud B, Girard PM. Antiretroviral therapy in resource-poor countries: illusions and realities. $A m \mathrm{~J}$ Public Health 2005; 95: 1117-1122.

4. Havlir DV, Hammer SM. Patents versus patients? Antiretroviral therapy in India. N Engl J Med 2005; 353: 749-751.

5. Kumarasamy $\mathrm{N}$, Vallabhaneni S, Flanigan TP, Balakrishnan $\mathrm{P}$, Cecelia A, Carpenter CC, et al. Rapid viral load suppression following generic highly active antiretroviral therapy in Southern Indian HIV-infected patients. AIDS 2005; 19: 625-627.

6. Laurent C, Kouanfack C, Koulla-Shiro S, Nkoue N, Bourgeois A, Calmy $A$, et al. Effectiveness and safety of a generic fixed-dose combination of nevirapine, stavudine, and lamivudine in HIV-1-infected adults in Cameroon: open-label multicentre trial. Lancet 2004; 364: 29-34.

7. Tuboi SH, Harrison LH, Sprinz E, Albernaz RK, Schechter M. Predictors of virologic failure in HIV-1-infected patients starting highly active antiretroviral therapy in Porto Alegre, Brazil. J Acquir Immune Defic Syndr 2005; 40: 324-328.

8. Hofer CB, Schechter M, Harrison LH. Effectiveness of antiretroviral therapy among patients who attend public HIV clinics in Rio de
Janeiro, Brazil. J Acquir Immune Defic Syndr 2004; 36: 967-971.

9. Braitstein P, Schechter M, Brinkhof M, Boulle A, Egger M, Dabis F. How do different types of treatment regimens affect short-term response to highly active antiretroviral treatment (HAART) among adults initiating treatment in low-income countries? [MoPe11.7C15]. 3rd International AIDS Society Conference on HIV Pathogenesis and Treatment. July 24-27; Rio de Janeiro; 2005.

10. Ivers LC, Kendrick D, Doucette K. Efficacy of antiretroviral therapy programs in resource-poor settings: a meta-analysis of the published literature. Clin Infect Dis 2005; 41: 217-224.

11. Coetzee D, Hildebrand K, Boulle A, Maartens G, Louis F, Labatala $\mathrm{V}$, et al. Outcomes after two years of providing antiretroviral treatment in Khayelitsha, South Africa. AIDS 2004; 18: 887-895.

12. Kumarasamy N, Solomon S, Chaguturu SK, Cecelia AJ, Vallabhaneni S, Flanigan TP, et al. The changing natural history of HIV disease: before and after the introduction of generic antiretroviral therapy in southern India. Clin Infect Dis 2005; 41: 1525-1528.

13. Lucas GM, Chaisson RE, Moore RD. Highly active antiretroviral therapy in a large urban clinic: risk factors for virologic failure and adverse drug reactions. Ann Intern Med 1999; 131: 81-87.

14. Detels R, Munoz A, McFarlane G, Kingsley LA, Margolick JB, Giorgi $J$, et al. Effectiveness of potent antiretroviral therapy on time to AIDS and death in men with known HIV infection duration. Multicenter AIDS Cohort Study Investigators. JAMA 1998; 280: 1497-1503.

15. Yamashita TE, Phair JP, Munoz A, Margolick JB, Detels R, O'Brien SJ, et al. Immunologic and virologic response to highly active antiretroviral therapy in the Multicenter AIDS Cohort Study. AIDS 2001; 15: 735-746. 